\author{
Available online at https://www.rjtl.org \\ Volume: 1, Issue: 2, 56-58, 2020 \\ ISSN: 2708-3632 \\ DOI: https://doi.org/10.46590/rjtl.2020.010205
}

\title{
Design \& Development of Garment for Chickenpox infected kids Using of Natural Herbs.
}

\author{
R. Ammu ${ }^{1}$, M. Jagatheesh ${ }^{1}$, K.Jayasri ${ }^{1}$, A. Sharmila ${ }^{1}$ and M. Jesima ${ }^{2}$ \\ ${ }^{1}$ Final Year Student, ${ }^{2}$ Assistant Professor, \\ Department of Fashion Technology, Sri Krishna Engineering College, Chennai-18, Tamil Nadu, India.
}

Paper History

Received : July 2020

Accepted : August 2020

Published : August 2020

Corresponding Author

R.Ammu

jayasrijk06@gmail.com

\begin{abstract}
Textiles are enforced fragment of human life. A new textile called medical textile which is the combination of medical science and textile technology. It causes harmful in several ways such as numerous skin disease and it affects all ages from neonates. Maintaining healthy skin is a needed thing for a healthy body. So the maintenance with natural treatment is cheap and claimed to be safe. For the production of new synthetic agents with the help of suitable raw material. In this system we are using Natural herbs like neem charcoal, screw pine flower, Curcuma longo particles and these were prepared with $100 \%$ cotton fabric. It is mainly used in kids garment for the application of antimicrobial finishing to protect chickenpox. This study makes way for usage of eco-friendly and dermatologically safe product produced using with natural herbs.
\end{abstract}

Keywords: Anti-Microbial, Chickenpox, Cotton Fabric

Citation: R. Ammul, M. Jagatheesh, K.Jayasri, A. Sharmilal and M. Jesima, Design \& Development of Garment for Chickenpox infected kids Using of Natural Herbs. Research Journal of Textile and Leather, 1(2), 56-58, 2020.

\section{INTRODUCTION}

Chickenpox is caused by the varicella-zoster virus, a member of the herpes family which is a generalized infection. It is characterized by a blistery rash. It affects children between the age of 5 and 8 years. Certain children facing risk for more severe disease. These mainly affect infants, children with immunodeficiency, and children undergoing treatment for cancer, and children on steroids [1].

Chickenpox is contacted by infected persons touching a normal person or anything that has been contaminated by contact with them. The virus is airborne so it may spread by an infected person by coughing and sneezing. The incubation period of chickenpox is 10-21 days and it is contagious from 1-2 days before the rash until all of the blisters have crusted $[2,7]$.

Treatment includes controlling of intense itching and control of fever. Anti-itching medications such as Benadryl and Atarax, topical lotions help in the reduction of itching; Acyclovir is an antiviral drug which can be used for this home care management can be done by frequent hand washing to prevent the complication of bacterial infection, using sandalwood oil for preventing scar from blemishing the skin. Neem leaves in bathwater provide healing effect and cures irritation $[3,8]$.

\section{MATERIAL AND METHODS}

\subsection{Materials}

Cotton is a vegetable fiber which gives warmth, feels and comfort especially to babies. Cotton fiber also has a good affinity towards the herbals. So $100 \%$ cotton fabric was selected for this study, and it was finished with neem-charcoal particles, screwpine, curcuma .

\subsection{Methods}

\subsubsection{Preparation of Fabric}

Firstly the cotton fabric was subjected to pre-washing cum relaxation process using the following recipe, to remove the added impurities in this fabric

$\begin{array}{lll}\text { Nonionic detergent } & : & 2 \mathrm{gpl} \\ \text { Time } & : & 20 \mathrm{~min} \\ \text { Temperature } & : & 70 \text { Degree Celsius }\end{array}$

At the end of the wash cycle, the prewashed fabric was removed from the washtub and then rinsed, dried at room temperature. The sample was taken for further treatment such as application with the neem-charcoal particles. 


\subsubsection{Preparation of Dye Powder}

The neem bark was dried under sunlight for about three days. Then the barks are ground into a fine powder.

\subsubsection{Boiling process}

The herbals were boiled well for one hour under a suitable temperature for deep penetration of the dye molecule into the water.

\subsubsection{Filtration}

The herbals were filtered by using pure cotton fabric to remove the dust particles and herbals bits.

\subsubsection{Dip and Dry process}

The prepared sample was dipped into the herbal solution. The solution was stirred well for better fixation for every 10minutes. The fabric was dipped in the solution for about 6-7 hours. Then the fabric sample is taken out, squeezed and dried for 12hours (shadow dry) without washing.

\section{RESULTS AND DISCUSSION}

\subsection{Anti-Bacterial Activity Test.}

The ASTM test method used to check the antimicrobial activity of immobilized antimicrobial agents under dynamic contact conditions is a sensitive test often used to measure the antimicrobial activity.

Two bacteria (i.e. S.aureus and E.coli) are uniformly distributed on the prepared Petri dishes; each Petri dishes with E.coli and S.aureus. The cotton fabric samples treated are put on the Petri dishes. This includes both unwashed and washed samples. All the agar plates are incubated for $24 \mathrm{hrs}$ at $37^{\circ} \mathrm{C}$. After 24hours the agar plates are assessed visually [4].

Table 1. Anti-Bacterial Activity Test.

\begin{tabular}{ll}
\hline Bacteria & Growth of bacteria(\%) \\
\hline Escherichia coliform & No Growth \\
Staphylococcus aureus & No Growth \\
\hline
\end{tabular}

It indicates that the treated fabrics have excellent efficacy of antimicrobial

\subsection{Abrasion Resistance}

Wear is generally considered to be the net result of several causes which reduces the serviceability of textile materials. Abrasion which is one aspect of the wear is caused by rubbing away of the component fibers and yarns of the fabric.

Abrasion is the wearing away of any part of a material by rubbing against another surface. The Eureka Martindale abrasion resistance tester plate was used to determine the abrasion resistance of the samples. The samples were cut from different places of the same material at random [5].
Table 2.Abrasion Resistance

\begin{tabular}{ll}
\hline Samples & $\begin{array}{l}\text { Abrasion Resistance } \\
\text { Grade }\end{array}$ \\
\hline Length (Wales) & Grade 4 \\
Width (Course) & Grade 3-4 \\
\hline
\end{tabular}

From the result, the treated samples have shown good abrasion resistance

\subsection{Colour Fastness to Washing}

A fabric that retains its colour during care and use is said to color fast state. The importance of colour fastness depends upon the use of the fabric. A specimen measuring $2 \times 4$ inch of the material to be tested in cut out. Each sample was placed between the undyed cotton samples which have been desized well. The 3 pieces are held together by stitching on all four sides. Soap solution of about $5 \mathrm{gpl}$ was prepared. Each of the samples was soaked in the soap solution separately for above $1 / 2$ an hour. After that, the test samples were removed rinsed in cold water thoroughly squeezed well and dried. The colour change and staining of the sample were assessed in compression with the greyscale [6].

Table 3. Colour Fastness to Washing

\begin{tabular}{lll}
\hline \multirow{2}{*}{ Samples } & \multicolumn{2}{l}{ Colour Fastness to Washing } \\
& Colour Change & Staining \\
\hline Cotton & $4 / 5$ & 4 \\
\hline
\end{tabular}

The results show that the washing fastness is found good.

\section{CONCLUSION}

The antimicrobial finish was given on $100 \%$ cotton plain-woven fabric using neem, Curcuma and pine flower using the dip and try the method. The finished sample had a good antimicrobial property for using chicken box infected kid's garment. The abrasionresistant and washing fast fastness property of the fabric were evaluated and the results were found good.

\section{REFERENCES}

[1]. Chickenpox hits Delhi, over 2,200 cases reported. (Friday, June 27, 2008). http://www.thaindian.com/newsportal/health/c hicken-pox-hits-delhi-over-2200-casesreported_10065352.htm.( Friday, June 27, 2008)

[2]. Ayoade F, Kumar S. Varicella Zoster (Chickenpox) [Updated 2020 Aug 11]. In: StatPearls [Internet]. Treasure Island (FL): StatPearls Publishing; 2020 Jan-. Available from:https://www.ncbi.nlm.nih.gov/books/NB K448191/

[3]. National Collaborating Centre for Women's and Children's Health (UK). Atopic Eczema in Children: Management of Atopic Eczema in 
Children from Birth up to the Age of 12 Years.

London: RCOG Press; 2007 Dec. (NICE

Clinical Guidelines, No. 57.) 7, Treatment. https://www.ncbi.nlm.nih.gov/books/NBK493

73/

[4]. Karthikeyan M Ramasamy, Ethiraj J, Abdurohman Mengesha Yessuf, Antimicrobial Efficacy of Chitosan Extracted From Cat Fish On Cotton Fabric,Journal of Environmental Science, Computer Science and Engineering \& Technology, A; Vol.9. No.1, 082-093.DOI: 10.24214/jecet.A.9.1.08293

[5]. Ramasamy, K.M. (2015), "Comparative Study of Organic and Regular Cotton Knitted Fabrics", Research Journal of Textile and Apparel, Vol. 19 No. 3, pp. 45-51.

[6]. Meaza Tadesse Keta ma, Karthikeyan M Ramasamy, Dr. Tewodros Brihanu, EfficiencyOf Ricinus Communis And RosmarinusOfficinalis L . Extracts On Cotton Fabrics And Its Physio Mechanical Assessments, International Journal Of Scientific \& Technology Research Volume 9, Issue 02, February 2020, pp.3448-3455.

[7]. International Journal of Science and Technology and Management Vol No .5, Issue No. 03. March 2016, ISSN NO 2394-1537.

[8]. Galli, E., Neri, I., Ricci, G., Baldo, E., Barone, M., Belloni Fortina, A., Bernardini, R., Berti, I., Caffarelli, C., Calamelli, E., Capra, L., Carello, R., Cipriani, F., Comberiati, P., Diociaiuti, A., El Hachem, M., Fontana, E., Gruber, M., Haddock, E., Maiello, N., ... Eichenfield, L. F. (2016). Consensus Conference on Clinical Management of pediatric Atopic Dermatitis. Italian journal of pediatrics,

26.https://doi.org/10.1186/s13052-016-0229-8.

[9]. Goncalves S., Dionne R.A., Moses G., Carrozzo M. (2019) Pharmacotherapeutic Approaches in Oral Medicine. In: Farah C., Balasubramaniam R., McCullough M. (eds) Contemporary Oral Medicine. Springer, Cham. https://doi.org/10.1007/978-3-31972303-7_11 